\title{
Leadership and Management in the Definitions of School Heads
}

\author{
By Jakub Kolodziejczyk*
}

In the literature on the subject there occur two approaches to describing mutual relationships between leadership and management. One of them perceives these phenomena as incompatible and evaluated as either positive or negative. Nowadays there is a general agreement that leadership and management are processes which cannot be separated from one another. It is emphasized that at the level of practical applications, it is impossible to separate the functions of leadership and the functions of management. From this perspective, the following questions are worth considering: in what manner do men of practice - head teachers define the notions of leadership and management within the context of their professional duties and what similarities and differences do they notice between these two notions? In order to answer these questions, we have analysed qualitative data collected during interviews with 171 head teachers of Polish schools. The results indicate that the respondents define management consistently based on the classical approach to the management functions. The definitions of leadership are more varied in their content, with a common core comprising a leader's vision and determination to realize such a vision.

Keywords: head teachers, leadership, management, Polish schools

\section{Introduction}

In the discussion of the differences between leadership and management, an important role was played by Abraham Zaleznik's article published originally in the Harvard Business Review in 1977, and subsequently reprinted in numerous publications. Paying attention to the significance of both managers' and leaders' contribution to the activities of organizations, Zaleznik emphasizes radical differences between them, from personal motivation through a way of thinking and acting, and concludes that "... managers and leaders are very different kinds of people" (Zaleznik, 1977, p. 68). According to the author, leaders are concentrated on change and pursuing new solutions, understanding people's convictions and ensuring their commitment, while managers are concentrated on maintaining stability and status quo, performing duties, exercising authority and achieving established goals.

One of the consequences of the differences between the characteristic features of leadership and management was their valuation (Bennis, 1989; Certo, 1997; Hull \& Ozeroff, 2004; Gill, 2011). Positively evaluated features associated with leadership such as focusing on people, exerting influence, inspiring trust, innovativeness, creativeness, determining directions or forward thinking were juxtaposed with negative qualities associated with management,

*Lecturer, Jagiellonian University, Poland. 
e.g. concentrating on systems and structures, controlling, copying of solutions or short-sightedness. In consequence of such valuation, some researchers presented leadership and management as standing in opposition to one another and considered the former as more desirable than the latter Managers do things right, while leaders do the right things (Bennis \& Nanus, 2007, p. 12). Too much management was identified as the reason for problems persisting in organizations and the development of leadership was proposed as an antidote for such corporate maladies (Zaleznik, 1989).

This point of view is shared by Bennis (1989): To survive in the twentyfirst century, we are going to need a new generation of leaders - leaders, not managers. The distinction is an important one. Leaders conquer the context - the volatile, turbulent, ambiguous surroundings that sometimes seem to conspire against us and will surely suffocate us if we let themwhile managers surrender to it. (p. 7)

Maccoby (2000) argues that although organizations need to perform the classically understood management functions, managerial positions in organizations may be redundant. Managerial positions can be taken over by team members who distribute among themselves particular management functions such as planning, budgeting, supervising performance quality or coordinating team meetings.

A different approach is presented by John Kotter (1990, 2001), who stresses that leadership and management are two different systems (processes) of operating in an organization which complement one another. As he understands it, leadership is related to changes in organizations and to dealing with such changes, while management concentrates on the creation of stability in organizational activities by way of dealing with complexity. According to Kotter, leadership consists of three processes (a) establishing directions of activities by developing an organization's vision; (b) aligning people with an organization's vision by its effective communication; (c) motivating and inspiring employees by way of empowerment to act despite possible obstacles. The processes making up leadership influence the creation of change in an organization.

As opposed to leadership, management consists of qualitatively different processes (a) planning and budgeting focused on the establishment of shortterm goals; (b) organizing and staffing by way of creating an organizational structure and allocating resources; (c) controlling and problem solving by way of monitoring the compliance of achieved results with previous plans.

Kotter (2001) summarizes the roles of leadership and management as well as their complementarity as follows: Leadership is different from management but not for the reason most people think. Leadership isn't mystical and mysterious. It has nothing to do with having "charisma" or other exotic personality traits. It's not the province of a chosen few. Nor is 
leadership necessarily better than management or a replacement for it. Rather, leadership and management are two distinctive and complementary activities. Both are necessary for success in an increasingly complex and volatile business environment. (p. 86).

It should be noted that the literature on the subject includes opinions of researchers who oppose the differentiation between leadership and management. Gosling and Mintzberg (2003) suggests that management is made up of various processes, while leadership performs a key role, but one of many roles, included in the scope of management, "...separation of management from leadership is dangerous" (p. 54). This opinion is strengthened by Yukl (2013), who claims that there are no reliable studies allowing one to conclude that there are differences between leadership and management.

The situation of head teachers, who are individually responsible for the functioning of their organizations, constitutes for them a challenge to create their own ideas of management and leadership. The objective of the conducted research is an attempt to establish in what manner people of practice - head teachers - define the notions of leadership and management within the context of their professional duties and what similarities and differences they notice between these two notions.

\section{Research Methodology}

The presented analyses come from a broader research into leadership in schools conducted within the scope of the "Leadership at School" project financed from the EU funds, whose main objective is to prepare a development and improvement model for educational leaders in Poland. The research was based on the mixed research methodology including research tools allowing for the collection of both quantitative and qualitative data. In the first part of the research, all head teachers in Poland were sent an invitation to take part in an electronic survey and asked to answer a series of questions concerning the significance of a number of competencies for leadership at school and to assess the degree of the respondent's possession of such competencies. The competencies included in the survey had been selected on the basis of the analysis of the literature on the subject. 2,824 (approximately 8\%) Polish school head teachers responded to the invitation. In the second stage of the research, a representative sample of 171 head teachers were selected at random and asked to participate in individual in-depth interviews. 


\section{Research Subjects}

The participants of the research were 171 head teachers:

- managing different types of educational institutions: 17 kindergartens (10\%), 64 primary schools (37\%); 18 lower secondary schools (11\%); 38 secondary schools $(22 \%) ; 28$ school complexes $(16 \%) ; 6$ others $(4 \%)$;

- $\quad$ with different lengths of tenure as educational managers: up to 5 years - 48 (28\%), 6-10 years - $55(32 \%)$; $11-15$ years - $39(23 \%)$; more than 15 years $-29(17 \%)$;

- of both sexes: 132 women (77\%), 39 men (23\%).

\section{Tool}

The analyzed data were collected during individual in-depth interviews conducted with the head teachers of schools and kindergartens during the 2013 summer holidays at places selected by the respondents (these places were the most often the head teacher offices). The interviews consisted of three parts. The first part comprised questions concerning the understanding of the notions of leadership and management as well as relationships between them. Questions in the second part were related to the understanding of the roles of the major areas of educational leadership. The third part focused on the deepening of knowledge of the leadership competencies considered by the respondents as their strengths and weaknesses as well as the methods of developing the required competencies.

\section{Method of Analysis}

The analysis comprised the respondents' answers to the following three questions included in the first part of the interview (a) How do you define the notion of "leadership"?; (b) How do you define the notion of "management"?; (c) What are the differences/similarities (mutual relationships) between these two terms?. The acquired answers underwent a qualitative analysis (Babbie, 2013) with a view to reconstructing the content of the respondents' understanding of the terms leadership and management as well as the relationships between these terms. For this purpose the research material was subject to inductive coding, which resulted in the creation of categories constituting a set of thematic scopes (Creswell, 2014) making up the understanding of each individual researched construct (notion) (a) leadership and (b) management as well as (c) relationships occurring between them. The analysis of each construct was limited to the content included in the answers to the subsequent questions relevant for a particular notion. 


\section{Results}

\section{The Content Scope of the Term "Management"}

The most general definitions proposed by the head teachers describe "management" as creating conditions for everyday work thanks to which the school achieves its goals.

In this sense, I associate management with organization, the best possible organization of the school's work ensuring, obviously, the school's orientation towards the best organization of education for the pupils, but also ensuring that the school employees feel good there and want to work there and, thanks to that, work better. (2622)

It consists in undertaking activities that are included in the classically understood management functions. Among them, the research participants place the heaviest emphasis on the aspect of work organization, while the most important role is played by the management of the school's material, financial and human resources.

Management that is an efficient organization of what one has at one's disposal: human resources, the school's assets, what the head teacher has at his disposal. (1652)

According to the head teachers, the measure of the good management of resources is the rationality and effectiveness of their utilization.

Management is the most rational and efficient use of resources remaining at the school's disposal. (2079)

In their definitions of management, respondents stress the importance of the function of planning supported by analyses of the available data, environment, needs and legal regulations. They emphasize the role of planning in the short- and mid-term perspectives, which results from the particular objectives of the educational system.

In this context, the most important thing is a proper planning process; it means a previous analysis of all data, an analysis of the environment, an analysis of needs; this should be followed by implementation activities, all in compliance with the law and regulations. (282)

Respondents refer to motivating as one of the tasks of management (the function of directing), but without stating precisely what motivating consists in. Another group focus on the roles of employee empowerment and cooperation among employees as means of influencing employees' behavior for the purpose of achieving the school's objectives. 
Motivating the people to do what the head teacher wants them to do, that is to work towards goals. (1147)

Management means, first of all, empowering others, supervising particular activities without too much interference, but also drawing conclusions and introducing possible changes. (1775)

Defining management, the head teachers participating in the survey place this notion in the context of legal regulations. They stress that the fulfillment of the managerial functions has to comply with the applicable legal regulations.

Management means running the school in accordance with the guidelines, the law and the regulations. (2005)

It is the fulfillment of all legal and other obligations related to the running of the school. (1260)

The basis for management is the knowledge of the law. It is the running of the school on the basis of the legal regulations.(1682)

This results in some respondents' concluding that in such a situation, a term more adequate than management is administration understood as the performance of bureaucratic procedures.

Management means running the school in accordance with the guidelines, the law and the regulations. (2005)

The basis for management is the knowledge of the law. It is the running of the school on the basis of the legal regulations.(1682)

This results in some respondents' concluding that in such a situation, a term more adequate than management is administration understood as the performance of bureaucratic procedures.

Management? I understand it as something of an administrative nature the whole documentation, tons of paper, plans, programmes... (193)

The graphic reconstruction of the content scope of the notion of management is presented in the Figure 1. 
Figure 1. Reconstruction of the Content Scope of the Notion of Management

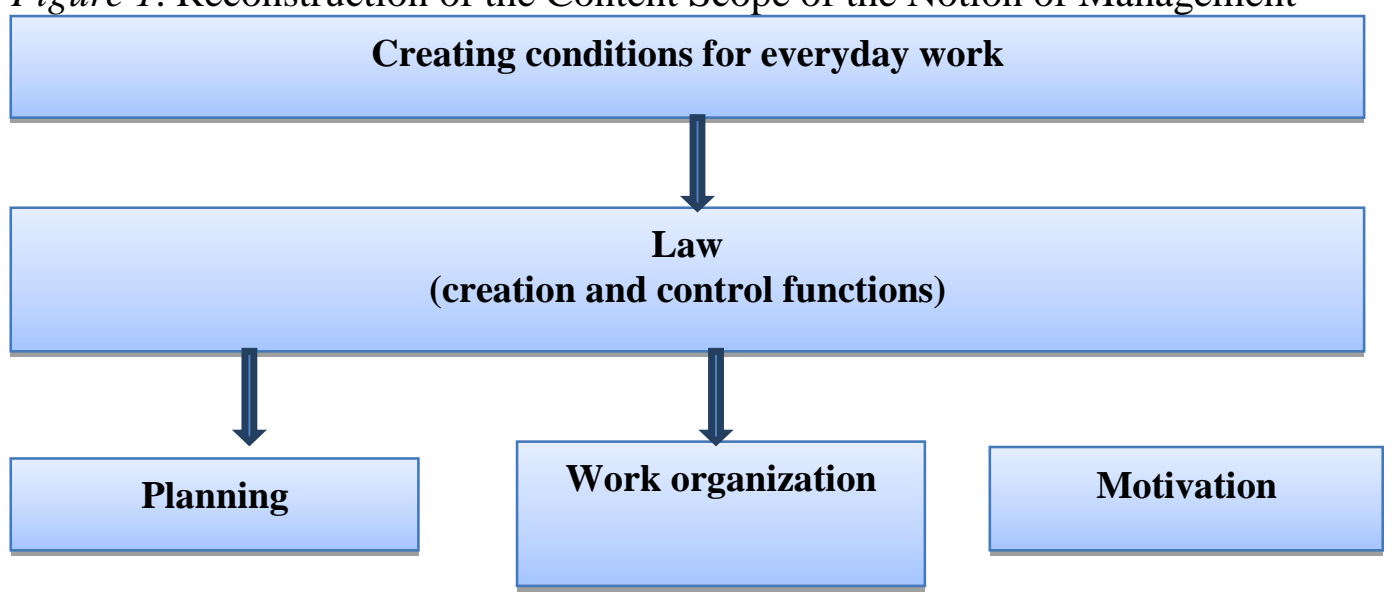

\section{The Content Scope of the Term "Leadership"}

There are two dominant ideas in the head teachers' statements about leadership analysed within the scope of this research. The first one distinguishes the leader as a person who has a vision of the school, and, by designing its future, establishes the direction for the organization's activity. Apart from having such a vision, the leader is also willing to take up activities necessary for its implementation.

A leader, simply a leader, is someone who has a vision and wants to realize such a vision in some way. (1374)

Well, a leader is a person who looks further into the future than the whole rest. (419)

The respondents present various opinions with respect to the manner in which the leader should involve employees in the vision's implementation. Some of them believe that it is essential to convince the employees to accept the vision as their own and to make them see their own benefit in it. Others emphasize exerting influence on employees through the leader's own involvement in the accomplishment of defined objectives, setting a good example, or they underline the importance of authority ensuing from the leader's charisma or trustworthiness.

For me, it is somebody who, thanks to their personality, commitment and attitude, will be able to persuade others to change their ways and to follow their example. (194)

Leadership is an ability to manage others, but on the basis of one's own authority, ... it is based on the charisma of a person who can manage other people and organize their work. (968) 
Formulating their own definitions of leadership, the head teachers also point out other perspectives of understanding this notion. These statements made by the head teachers may be classified in two categories: development support and team management. In the former, emphasis is put on the leader's role in taking care of and supporting the personal and professional development of pupils and teachers, discovering their potential and offering assistance in overcoming obstacles.

In my opinion, leadership is releasing people's potential and maximizing such potential for the benefit of a given enterprise or an educational institution. (2174)

In the perception of the leader as a team manager, the most important aspects are the establishment of the team's objectives, the use of interpersonal skills and the ability to develop cooperation, which should contribute to effective teamwork in order to achieve the established objectives.

It is a certain skill to manage a team... (1834)

A leader is a person who simply possesses certain qualities which allow him to manage a team of people relatively efficiently. (477)

The graphic reconstruction of the content scope of the notion of leadership is presented in the Figure 2.

Figure 2. Reconstruction of the Content Scope of the Notion of Leadership

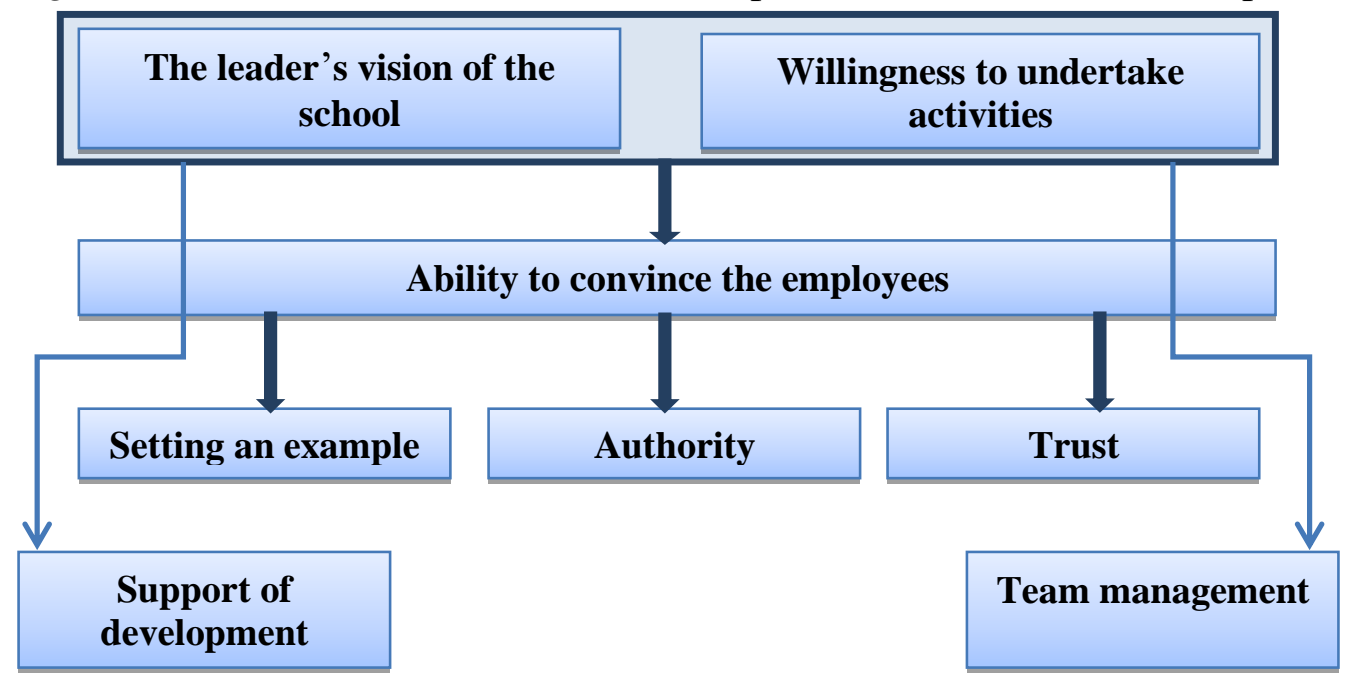

\section{Relationships between Leadership and Management}

The interrelation between leadership and management is the most distinct keynote in the respondents' statements. It is expressed in various forms. One of them presents leadership and management as two different elements which are, however, inextricably connected. 
These two terms (leadership and management-author's note), which have a lot in common, are connected inextricably. (234)

Some respondents notice a mutual connection between leadership and management, or even the fact that one results from another. There are two possible directions for this connection (a) leadership is necessary for the occurrence of good management; (b) proper management is essential for leadership to arise.

Certainly, leadership ensues from management. First, all conditions for management have to be fulfilled before some type of leadership can be subsequently created. (2210)

Well, the relationship is that if you want to manage effectively, you need to be a leader. Because it helps a lot. On the other hand, you can be a leader irrespective of management. (1508)

In some respondents' statements, the borderlines between leadership and management are blurred, and thus the terms become equivalent or they are treated as synonyms.

Leadership cannot be separated from management; I think that there should be one common term referring to both management and leadership. (2005)

A particular way of simultaneously considering leadership and management as being equivalent and differentiating between them is treating them as being equivalent in terms of content, but referring the former to theory and the latter to practice:

Leadership is a concept, a theory, while management is its practical application... (1494)

The interrelation between leadership and management is also considered by the respondents in terms of a scope of activities and responsibilities. Leadership is presented as a term comprising a wider scope of the head teacher's responsibility for everything that happens at school, while management applies to a narrower scope, a fragment of the school's functions, or the areas requiring compliance with the legal regulations:

I think that leadership is a little bit more than management; we've spoken here about how to communicate your objectives and make people follow you, which means that we build goals, create goals, become aware of the necessity of changes, are able to dispel the fear of change. (336) 
The analysed material contains also statements which indicate the opposite way of understanding the scope of interrelations between leadership and management, i.e. one in which management has a broader scope than leadership. These statements are not specific enough for the researcher to grasp clearly the mentioned differences.

The differences in defining leadership and management are reflected in the way of perceiving leaders' and managers' personalities as well as identifying the source of their knowledge and skills (Table 1). Traits related to leadership are rooted in personality, in a person's inherent qualities. They ensue from the values embraced by leaders, from their ability to reflect deeply on their own experience, from their inherent qualities which predispose them to lead, from a sense of mission which they have to complete. Unlike leaders, managers acquire competences in the process of learning; such competences are external, objective knowledge (e.g. included in literature).

Leadership is a person's individual traits, predispositions. Management can be learnt, or read about, as it were. (1132)

Leadership requires some personality traits related to an axiological system, while management consists in using various means or resources, also penalties, to achieve a particular goal. (60)

Table 1. The Differences in Defining Leadership and Management

\begin{tabular}{|l|l|}
\hline Leadership & Management \\
\hline $\begin{array}{l}\text { A broader scope of activities and } \\
\text { responsibilities }\end{array}$ & $\begin{array}{l}\text { A narrower scope of activities and } \\
\text { responsibilities }\end{array}$ \\
\hline $\begin{array}{l}\text { Productive (creating a vision, } \\
\text { encouraging people to work) }\end{array}$ & $\begin{array}{l}\text { Reproductive (routine, bureaucratic } \\
\text { activities) }\end{array}$ \\
\hline Human personality is the source & One can learn it \\
\hline Individual character & Collective character \\
\hline
\end{tabular}

The respondents relate the type of work to the differences presented above. Creating a vision and persuading people to participate in its realization is associated with leadership. Management is perceived as a craftsman's work: routine, imitative, bureaucratic activities.

In leadership, it appears to me, we need more a leader who creates a certain model for all others to follow. Management is, however, I would say, on a certain flat level, which means that what is necessary is a skilful organizer who can put different blocks together into a functioning whole this is the fundamental difference. (2662)

The head teachers perceive the way of exercising leadership in different ways, too. Firstly, and more frequently, they stress the individual (personal, one-man) character of leadership, while management is perceived as a process involving many people. 
In leadership there is no such cooperation among employees. Management is cooperation. An employee and a manager cooperate with one another. (2492)

Leadership is associated with the individual's power (often authoritarian power: I associate a leader with an autocratic person (251)), as well as oneman responsibility.

Some respondents present these relations in an opposite way, perceiving leadership as a group process and management as an activity performed by an individual. It is connected particularly with the way of perceiving the managing person as one who is legally responsible for their decision. Leadership, on the other hand, is connected with cooperation, exerting influence on employees, yet outside the scope of the law.

I associate management more with a head teacher making a decision and that's it, while leadership is more about leading a group in a particular direction in order to achieve a desired effect. (2648)

\section{Conclusions}

The reconstructed content of the term management as reflected in the head teachers' responses is coherent and comprises a limited set of recurring themes. It is also consistent with the definition of this term included in the classically understood management functions (planning, organizing, managing, controlling). This results undoubtedly from the head teachers' personal experiences related to their professional careers and the dominant model of head teacher education based on the paradigm of the universalist theory of management sciences (Bogacz-Wojtanowska \& Sasak, 2014). An additional content-related element of the head teachers' statements is the legal aspect, which, on the one hand, may be interpreted as a controlling function of management, and on the other hand, it may constitute formal requirements which the head teachers strive to fulfill as the superior management idea.

The necessity to follow the legal regulations, their ever increasing number, as well as their individual responsibility for regulatory compliance force the head teachers to make some bitter conclusions, that soon there will be no volunteers for head teacher positions.

The understanding of the term leadership is characterized by a more diversified content and less coherence. The core of this construct is found in two characteristics (a) the leader's vision of the school; and (b) his willingness to accomplish it. The ways in which employees are being involved in activities aiming at the realization of the vision, such as persuasion, setting an example, authority, and trust are presented in different ways. Elaborating on the definition of leadership, the head teachers also emphasize other components of this term, such as development support and team management. The head 
teachers' definitions of leadership may be interpreted on the basis of the categories of these concepts according to which the leader is the most important player (the classical, transactional, and visionary paradigms), as opposed to the organic paradigm in which leadership can be exercised by a group or distributed among many people (Avery, 2004).

The distinct differences in the content of the definitions of management and leadership have been reflected in the answers to the question about the similarities and differences between them, which may also be a complement to the described terms. The differences between management and leadership can be interpreted in the manner proposed by Kotter (1990), i.e. as two different, but mutually complementing processes. The variety of the ways of defining the similarities and differences between leadership and management proves that some practitioners share also a model (construct) in which the terms are considered as synonymous. There is also an approach in which leadership and management are juxtaposed, in particular in the description of the leader's and the manager's respective personalities, as well as the sources of their inherent and acquired competences. In conclusion, it can be stated that all manners of differentiating between leadership and management presented in the introduction on the basis of a review of the literature on the subject are present in the statements of the survey participants.

The head teachers' statements appear to reflect a profound dilemma between being a manager and being a leader. One could assume that the head teachers' clearer conceptualization of the notion of management is the consequence of the previous educational system and the requirements of the educational law, which the head teachers approach with great respect. It is not helpful in the development of a balanced concept of leadership. Operating in flattened organizational structures in which they have to perform simultaneously many roles and facing the dilemma whether to be a leader or a manager, the head teachers more often choose the latter.

\section{References}

Avery, G. C. (2004). Understanding Leadership: Paradigms and Cases. London: Sage.

Babbie, E. (2013). The Basics of Social Research. Wadsworth, CA: Cengage Learning.

Bennis, W. G. (1989). Managing the dream: Leadership in the 21st century. Journal of Organizational Change Management, 2(1), 6-10.

Bennis, W. G., \& Nanus, B. (2007). Leaders: The Strategies for Taking Charge. New York, NY: HarperCollins.

Bogacz-Wojtanowska, E., \& Sasak, J. (2014). Diagnoza ksztatcenia i doskonalenia kadry kierowniczej szkót/placówek oświatowych $w$ Polsce. [A Diagnosis of Educating and Improving the Managerial Personnel of Schools/Educational Institutions in Poland.] Retrieved from http://bit.ly/1diFCVQ

Certo, S. C. (1997). Modern Management. Diversity, Quality, Ethics, and the Global Environment. New Jersey, Upper Saddle River: Prentice Hall.

Creswell, J. W. (2014). Research Design: Qualitative, Quantitative, and Mixed 
Methods Approaches. Thousand Oaks, CA: Sage.

Gill, R. (2011). Theory and Practice of Leadership. London: Sage.

Gosling, J., \& Mintzberg, H. (2003). The five minds of a manager. Harvard Business Review, 81(11), 54-63.

Hull, T., \& Ozeroff, P. (2004). The Transitioning from Manager to Leader. New York, NY: Harper and Row.

Kotter, J. P. (1990). A Force for Change: How Leadership Differs from Management. New York, NY: Free Press.

Kotter, J. P. (2001). What leaders really do? Harvard Business Review, 79(11), 85-98.

Maccoby, M. (2000). Understanding the difference between management and leadership. Research Technology Management, 43(1), 57-59.

Yukl, G. (2013). Leadership in Organizations. New York, NY: Pearson Prentice Hall.

Zaleznik, A. (1977). Managers and leader: are they different? Harvard Business Review, 55(5), 67-78.

Zaleznik, A. (1989). The Managerial Mystique: Restoring Leadership in Business. New York, NY: Harper and Row. 
